\title{
The dynamics of fiscal policy in Algeria: sustainability and structural change
}

\author{
Abderrahim Chibi ${ }^{1 *}\left(\mathbb{0}\right.$, Sidi Mohamed Chekouri ${ }^{1}$ and Mohamed Benbouziane ${ }^{2}$
}

*Correspondence:

chibirahim@yahoo.fr

${ }^{1}$ Faculty of Economics

and Management, University

Centre of Maghnia, Maghnia,

Algeria

Full list of author information

is available at the end of the

article

\begin{abstract}
This study focuses on the empirical tests for the sustainability and solvency of fiscal policies in Algeria using a nonlinear model approach, based on quarterly data from 1963Q1 to 2017Q1 on the Algerian budget balance-GDP. Empirical evidence indicates that the adjustment behavior of the budget balance has nonlinear characteristics in the form of a Logistic model depending on the oil price. On the other hand, unit-root tests (linear, nonlinear, and with structural break) accept the null hypothesis of the unit roots. This means that the time series of budget balance is not stationary (not mean reverting characteristic), and therefore cannot sustain the budget deficit in Algeria over the long term. This suggests that Algerian government needs to pay more attention to the fiscal policy and efficiently control the budget deficit to avoid the debt crisis.
\end{abstract}

Keywords: Fiscal policy, Sustainability, Structural breaks, Nonlinear model, Stationarity JEL Classification: E62, H62, C22

\section{Introduction}

The issue of fiscal deficits and their sustainability is of great analytical and empirical interests to both academicians and policy makers. From the theoretical perspective, a large and growing fiscal deficit would lead to a worsening of the current account and appreciation of the real exchange rate.

From a policy standpoint, determining whether the fiscal balance is on a sustainable path over time is important because the reply to this inquiry may indicate the requirement for policy reform before the imbalances become insolvent and lead to a hard landing. On the other hand, measuring sustainability of the fiscal deficit has been a highly contentious issue. Recent advancements in time series techniques, notably nonlinear modeling, allow analysts to re-examine the fiscal process and determine whether the fiscal balance is on a sustainable path.

After the financial crisis of 2008-2009, the public debt of many countries has been on a steep upward trajectory due to implementation of various stimulus and relief packages directed toward financial sector and the economy as a whole. In fact, some European countries like Greece, Ireland, Portugal, Spain, and Italy are actually in serious dilemma with their public finances, which is reflected in the high yield demanded from the government bonds of these countries. 
As far as Algeria is concerned, the fiscal and external balances have deteriorated significantly due to higher spending and lower hydrocarbon revenue (The impact of the oil price shock since 2014). The fiscal deficit has widened significantly during the last 5 years, as it moved from the 1.2\% of GDP in 2011 to $13.5 \%$ in 2016 (45.3\% of NHGDP). To meet large financing needs over the medium term with savings in the FRR near the statutory floor of DA 740 billion, Algerian authorities launched a domestic debt issue in first April 2016 as it seeks to diversify financing sources and also aimed at mobilizing savings in the informal sector. The debt, with a maturity period of 3-5 years, will carry an interest rate of 5.0-5.75\%. Despite all the available means, the public authorities have succeeded in attracting only 400 billion dinars, or the equivalent of $\$ 3.6$ billion ( $36 \%$ of the value must be collected). While this process aimed to recruit financial resources of up to $\$ 10$ billion (It is the one-third of budget deficit which was estimated at $\$ 30$ billion). As a result, central government debt has increased significantly to $27 \%$ of GDP at the end-2017.

In 2018, the authorities changed their economic strategy. They adopted an expansionary budget for 2018 aimed at clearing arrears and supporting public investment. Reluctant to borrow externally or let the exchange rate depreciate at a faster pace, they decided to monetize their financing needs and harden import barriers. The banking law was changed in October 2017 to allow for 5 years Bank of Algeria (BA) to finance directly, among others, the budget deficit, public sector debt buy-back, and the National Investment Fund (FNI). By the end of 2018, monetary financing may reach the equivalent of about $23 \%$ of 2017 GDP. In an environment where external risks remain tilted to the downside, this new strategy may further exacerbate macroeconomic imbalances as it risks increasing inflationary pressures.

All of these challenges require us to ask the following important questions: First, are Algerian public finances meeting their intertemporal budget constraint? Second, is the sustainability of budget deficits robust to structural breaks and/or shifts in fiscal policy regimes? Third, is there any evidence of asymmetric and/or nonlinear fiscal adjustment back to equilibrium? And what is the speed of the process of fiscal consolidation?

In this context, the aim of this paper is to analyze the technical basis of financial soundness and state solvency, and provide some evidence on the sustainability of budget deficits in Algeria, especially when fiscal policy is conducted as a nonlinear process, which has been hardly treated in the literature.

The remainder of this paper is organized as follows: section two deals with the theoretical foundation of fiscal sustainability, whereas a descriptive analysis of fiscal framework considerations in Algeria is presented in section three. Detailed empirical evidence is presented in section four. Section five focuses on the methodology used as well as the main results. The last section proposes some conclusions and recommendations for decision-makers. 


\section{Theoretical issues}

For a long time, the issue of sustainability has been addressed only in terms of the effects of public debt ${ }^{1}$ on the economy. According to Hume, public debt was likely to lead to injurious tax increases in the short term and possibly to default in the long term. Smith also considered that debt financing would lead to default. The consensus view was that debt financing was to be used only under exceptional circumstances, such as wars. ${ }^{2}$ At the beginning of the 1920s, when writing about the public debt problem faced by France, Keynes mentioned the need for the French government to conduct a sustainable fiscal policy in order to satisfy its budget constraint. Keynes stated that the absence of sustainability would be evident when "the State's contractual liabilities (...) have reached an excessive proportion of the national income."

In the literature, there is a lack of clear consensus among economists about the definition of public finance sustainability. In fact, many research papers in the area of sustainability introduce their own criteria for sustainability that are in many ways similar but not identical. ${ }^{3}$ One definition is that a government should be able to meet its obligations if and when they arise in the future (i.e., can be continued into the projected future without any changes in taxation or spending patterns). Sustainability will therefore also depend on a government's future revenue (with which it might be able to meet its obligations) and the timing of the future obligations. The ability to meet obligations when they arise means that a government should consider debt financing only as long as the debt burden remains at a prudent level. The definition is therefore in the spirit of the Government's sustainable investment rule.

According to Blanchard (1990), sustainability is about whether, based on current fiscal policy, a government is headed toward excessive debt accumulation. To make this general statement executive, Blanchard defines sustainable fiscal policy as a strategy that ensures that the ratio of debt to GDP converges back toward its initial level. A similar definition is provided in Buiter (1985), who calls a fiscal policy sustainable if it maintains the ratio of government net worth to GDP at the present level.

The requirement of convergence of the debt ratio toward its initial level is only a special case of a more general definition, which states that fiscal policy is sustainable if the present value of future primary surpluses is equal to the current level of debt. The latter strand of criticism led some authors (e.g., Artis and Marcellino 2000; IMF 2002) to distinguish between solvency and sustainability. The government is said to be solvent if it is capable, over an infinite time horizon, of paying its debt via future primary surpluses. In other words, the government is solvent if the intertemporal budget constraint (IBC) is fulfilled. On the other hand, according to Artis and Marcellino, sustainability is

\footnotetext{
${ }^{1}$ Debt sustainability framework covers external and domestic public and publicly guaranteed (PPG) debts which comprise (i) debt of the public sector, defined as central, regional, and local governments, central bank, and public enterprises-the latter subsumes all enterprises that the government controls, such as by owning more than half of the voting shares - and (ii) private sector debt guaranteed by the public sector. Excluding an SOE's external debt from the external DSAs can be considered, if the company can borrow externally without a public guarantee and its operations pose a limited fiscal risk.

2 Also Smith discussed fiscal illusion and the merit of expenditures to be deficit-financed.

3 A good survey is provided in Balassone and Monacelli (2000), Krejdl (2006) and Sarvi (2011).
} 
a somewhat more imprecise concept referring to the possibility of the government under current policies achieving a prespecified debt ratio in a finite time horizon. ${ }^{4}$

Consequently, to assess public finance sustainability, there are seven different approaches: summary indicators of sustainability, econometric tests, Value-at-Risk framework, fiscal limits and fiscal space, general equilibrium models, "Fan-Chart" Approach, and generational accounting. Each approach is described and analyzed based on research found in the literature]; for more details, see Sarvi (2011).

Summary indicators ${ }^{5}$ are the most commonly used practical tool used in sustainability assessments. They are based on projections of future public debt, and give the budgetary adjustment which is required to satisfy the IBC or reach a target debt level. Econometric tests are statistical tests for various theoretical sustainability criteria that can be used to determine whether a given criterion holds in the data. ${ }^{6}$ Value-at-Risk framework uses stochastic simulations of the public sector balance sheet to study the degree of public sector solvency. It gives an estimate of a probability distribution for government's future net asset position. ${ }^{7}$ Fiscal limits ${ }^{8}$ and fiscal space ${ }^{9}$ attempt to estimate a public debt ceiling for a country based on assumed constraints to government's fiscal policies. General equilibrium models ${ }^{10}$ are detailed large-scale frameworks which assess sustainability based on comprehensive modeling of the whole economy. Generational accounting ${ }^{11}$ analyzes sustainability by comparing the net tax burden of current and future generations. Fan charts ${ }^{12}$ summarize risks to debt dynamics by representing the frequency distribution of a large sample of debt paths generated by means of stochastic simulations, and derived from the "marriage" between the pattern of shocks on the one hand and the endogenous response of fiscal policy on the other.

The most straightforward way to assess the fiscal sustainability position is to start from a government's intertemporal budget constraint. The one-period government intertemporal budget constraint can be written in nominal terms as:

$$
G_{t}-T_{t}+i_{t} B_{t-1}=\Delta B_{t}+\Delta M_{t}=-S_{t}
$$

where $G$ :government expenditure, $T$ : tax revenue, $B$ : government debt at the end of period $t, M$ : monetary base, $S$ : total budget surplus, $i$ :interest rate on government debt. The correct implementation of the budget constraint requires the use of the net market value of debt. Net debt is defined as gross debt minus financial assets. Dividing each term in (1) by nominal GDP we obtain the budget constraint in terms of proportions of GDP:

\footnotetext{
4 The distinction between finite and infinite horizons will be important when it comes to defining the various sustainability indicators.

5 These indicators are Finite and infinite horizon tax gap indicators (equivalent to the S1 and S2 indicators used by the European Commission), Financing gap (Giammarioli et al. 2007), Primary gap (Buiter 1985).

6 See the following "Empirical literature" section.

7 See Barnhill and Kopits (2003) and Sarvi (2011).

8 This approach appears in Bi (2012), Cochrane (2011) and Leeper and Walker (2011).

9 This approach developed by Ostry et al. (2010).

10 Three papers analyze public finance sustainability by using general equilibrium overlapping generations (GE-OLG) model by Fernandez-Huertas Moraga and Vidal (2004), application of applied GE-OLG model by van Ewijk et al. (2006), and application of computable GE-OLG model by Andersen and Pedersen (2006).

11 See Auerbach et al. (1991), Gokhale (2008), and Sarvi (2011).

12 See IMF $(2011,2013)$.
} 


$$
g_{t}-\tau_{t}+\left(i_{t}-\pi_{t}-\eta_{t}\right) b_{t-1}=\Delta b_{t}+\Delta m_{t}+\left(\pi_{t}+\eta_{t}\right) m_{t-1}=-s_{t}
$$

where the lower-case letters $g, \tau, b, m$, and $s$ denote the ratio of the corresponding uppercase variables to nominal GDP, $\pi_{t}=\left(p_{t}-p_{t-1}\right) / p_{t-1}$ and $\eta_{t}=\left(Y_{t}-Y_{t-1}\right) / Y_{t-1}$ with $P$ and $Y$ standing for the price level and real GDP, respectively. Equation (2) says that the interest-inclusive government deficit is financed by new bond issues, base-money creation, and seignoirage. Equation (2) can be written as:

$$
d_{t}+\rho_{t} b_{t-1}=\Delta b_{t}
$$

where $d_{t}=g_{t}-\tau_{t}-\Delta m_{t}-\left(\pi_{t}+\eta_{t}\right) m_{t-1}$ is the primary government deficit expressed as a proportion of nominal GDP, and $\rho_{t}=i_{t}-\pi_{t}-\eta_{t}$ is the real ex post interest rate adjusted for real output growth. Equation (3) is an identity which holds ex post in time $t$. If $\rho_{t}\langle 0$ for all $t$ then Eq. (3) is a stable difference equation which can therefore be solved backward. This implies that the debt-GDP ratio $b_{t}$ remains finite for any sequence of finite primary deficits $d_{t}$. For constant $\rho_{t}$ and $d$, the steady-state value of $b=-d / \rho_{t}$. But if $\rho_{t}>0$ for all $t$, the debt-GDP ratio will eventually explode for $d_{t}>0$. To avoid this, primary surpluses are required (i.e., $d_{t}\langle 0)$. In this case, $(3)$ must be solved forward and the intertemporal budget constraint obtained in order to determine whether the sum of expected future discounted surpluses are sufficient to meet the current level of the debtGDP ratio. For constant $\rho_{t}$ and $d\left(d_{t}\langle 0)\right.$ again $b=-d / \rho_{t}$.

To obtain the intertemporal budget constraint, first we re-write the budget constraint for period $t+1$ in ex ante terms as

$$
b_{t}=E_{t}\left[\left(1+\rho_{t+1}\right)^{-1}\left(b_{t+1}-d_{t+1}\right)\right] \text {, }
$$

where $b_{t}$ is known in period $t$, and expectations are taken conditional on information at time $t$. Solving (4) forward and successively substituting out the future compound discounted debt-GDP ratio gives the $n$-period intertemporal budget constraint:

$$
b_{t}=E_{t} \delta_{t, n} b_{t+n}-E_{t} \sum_{i=1}^{n} \delta_{t, i} d_{t+i}
$$

where $\delta_{t, n}=\int_{s=1}^{n}\left(1+\rho_{t+s}\right)^{-1}$ is the time-varying real discount factor $\mathrm{n}$ periods ahead, adjusted for real GDP growth rate. $\delta_{t, n}$ can also be written as $\delta_{t, n}=\alpha_{t+n} / \alpha_{t}$ where $\alpha_{t}=\int_{i=1}^{t}\left(1+\rho_{i}\right)^{-1}$. Normalizing $\alpha_{t}=1$, and Defining $X_{t}=\alpha_{t} b_{t}$ and $Z_{t}=\alpha_{t} d_{t}$ as the discounted debt-GDP and primary deficit-GDP ratios, respectively, enables Eq. (5) to be written as:

$$
\alpha_{t} b_{t}=E_{t} \alpha_{t+n} b_{t+n}-E_{t} \sum_{i=1}^{n} \alpha_{t+i} d_{t+i} \quad \text { or as } \quad X_{t}=E_{t} X_{t+n}-E_{t} \sum_{i=1}^{n} Z_{t+i}
$$

The one-period budget constraint, Eq. (3), can also be written in discounted terms as:

$$
Z_{t}=\Delta X_{t}
$$

and Eq. (4) can be written as: $X_{t}=E_{t}\left(X_{t+1}-Z_{t+1}\right)$.

A necessary and sufficient condition for sustainability is that as $n$ goes to infinity the discounted value of the expected debt-GDP ratio converges to zero. This is also known 
as the transversality condition, and implies that no Ponzi games (NPG) are allowed, meaning no new debt is issued to meet interest payments. This condition can be expressed as:

$$
\lim _{n \rightarrow \infty} E_{t} \delta_{t+n} b_{t+n}=\lim _{n \rightarrow \infty} E_{t} X_{t+n}=0 .
$$

It then follows that the current debt-GDP ratio is offset by the sum of current and expected future discounted surpluses expressed as a proportion of GDP, implying that the government budget constraint holds in present value terms ${ }^{13}$ with:

$$
b_{t}=-\lim _{n \rightarrow \infty} E_{t} \sum_{i=1}^{n} \delta_{t, i} d_{t+i}
$$

or

$$
X_{t}=-\lim _{n \rightarrow \infty} E_{t} \sum_{i=1}^{n} Z_{t+i}
$$

Two things are important to note. First, the transversality condition, Eq. (8), does not require that the debt-GDP ratio goes to zero, only that it does not grow faster than the growth-adjusted real discount rate. In principle, current debt can be sustained by any sequence of primary deficits or surpluses that satisfies Eqs. (9) and (10), meaning that they offset the current level of debt. Second, if fiscal policy were not sustainable, a future policy change would be required in order to satisfy the transversality condition. Provided this change of policy is expected at time $t$, Eq. (9) can still hold even though the process that generating the primary deficit would not then be structurally stable in the sense that the future policy change would cause a structural break (Uctum and Wickens (2000), p. 202)

In this regard, more recent work has emphasized the importance of nonlinearity in fiscal policy. This nonlinearity may arise if we expect fiscal authorities to react differently to whether the deficit has reached a certain threshold deemed to be unacceptable or unsustainable (Statistically, this implies that the variable may behave as an I(1) process within the aforementioned threshold). Bertola and Drazen (1993) elaborate a framework which allows for trigger points in the process of fiscal adjustment, such that significant adjustments in budget deficits may take place only when the ratio of deficit output reaches a certain threshold. ${ }^{14}$ This may reflect the existence of political constraints that block deficit cuts, which are relaxed only when the budget deficit reaches a sufficiently high level deemed to be unsustainable (Bertola and Drazen 1993; Alesina and Drazen 1991). ${ }^{15}$ In general, three reasons make timely fiscal adjustment unlikely to occur: political polarization, conflicting distributional objectives between different socioeconomic

\footnotetext{
${ }^{13}$ Whether $Z_{t}$ is a strongly or weakly exogenous process, a necessary and sufficient condition for the transversality condition given by (9) to be satisfied is that, if $X_{t}$ is structurally stable, then it should be a zero-mean stationary process.

14 This state dependent two regime process will imply that the further the fiscal balance deviates from the equilibrium, the faster will be the mean reversion.

15 For more details, see: Chibi et al. (2014).
} 


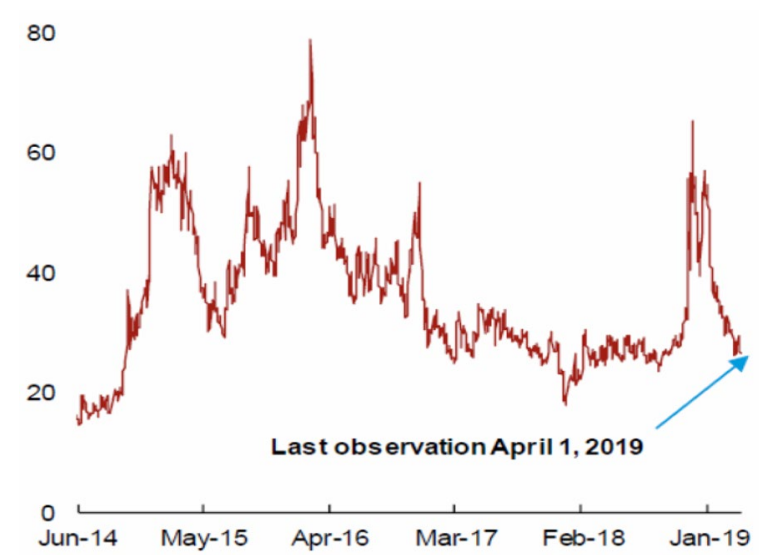

Fig. 1 The CBOE (Chicago Board Options Exchange) crude oil volatility index (Source: IMF (2019) (Middle East and Central Asia Department): Regional Economic Outlook. April 2019. p. 7)

groups in relation to the burden of budgetary retrenchment, and political stalemate over distribution.

For resource-rich countries, and with the expected depletion of hydrocarbon resources over the next years, a fiscal framework should provide a set of tools to achieve two interrelated objectives: (i) ensure long-term sustainability and intergenerational equity, and (ii) manage revenue volatility and uncertainty. In this context, The IMF (2012) has developed a new toolkit for designing fiscal rules that aim to smooth revenue volatility and ensure long-term fiscal sustainability in resource-rich countries. The toolkit includes intergenerational equity and price-based rule models.

The starting point of the long-term sustainability analysis is the permanent income hypothesis (PIH). The PIH assumes that a country maintains a constant ratio of the nonhydrocarbon primary balance (NHPB) to NHGDP, equal to the implicit return on the present value of future natural resource revenue plus accumulated net financial savings ${ }^{16}$. The computation basically transforms resource wealth on the ground into "virtual" financial wealth and uses an implicit rate of return. Total resource wealth is then computed as the sum of existing financial wealth and future resource revenues, measured in net present value.

\section{Fiscal framework considerations in Algeria}

The drop of oil price since mid-2014 has been spectacular: prices have fallen nearly $70 \%$ to about $\$ 40$ a barrel (see Fig. 1). ${ }^{17}$ This sharp decline in crude oil prices has eroded Algerian finances, trade balance, and international reserves. Fiscal deficits have been rising from 1.4\% of GDP in 2013 to 16.2\% of GDP in 2015. Lower oil prices have resulted into a $30 \%$ decline in hydrocarbon revenues, while spending grew by $10.2 \%$, driven by a

\footnotetext{
${ }^{16}$ IMF (2014) Simulations indicate that the Algerian NHPD consistent with the PIH rule would be 11\% of NHGDP. For long-term sustainability analysis in resource-rich countries, the non-resource primary balance (NRPB) is a good measure of the macro-fiscal stance. The NRPB identifies the impact of government operations on domestic demand, because resource revenues typically originate abroad.

17 Renewed oil price volatility reflects supply disruptions, global growth concerns, technological changes, and geopolitical uncertainties.
} 
surge in capital spending. The deficit was mainly financed by drawings from the Fonds de Régulation des Recettes (FRR), ${ }^{18}$ Algeria's oil saving fund, which declined to $12.3 \%$ of GDP from a peak of 34.3\% in 2009 (see Fig. 2).

Since 2009, despite abundant liquidity, the fiscal deficits of the Algerian central government have been financed mainly by borrowing from public entities and drawing down fiscal savings. From 2009 to 2016, Algeria recorded a cumulative fiscal deficit of 8.297 billion dinars (equivalent to $\$ 75$ billion). Of this amount, $46 \%$ was financed using the deposits of public entities-a practice tantamount to central government borrowing but not reflected in government debt statistics. ${ }^{19}$ Another $42 \%$ was financed by drawing down savings in the FRR. The deposits of public entities financed the bulk of deficits during 2009-2013, whereas savings in the FRR have been the main source of financing in the last 3 years. Only $6 \%$ of the cumulative deficit was financed by net domestic debt issuance. ${ }^{20}$ Net foreign borrowing has been negligible.

In 2015, the balance of payments deficit reached about $\$ 27.57$ billion and more than $\$ 30$ billion by the end of this year. Total reserves have fallen from \$194 billion in 2013 to an estimated $\$ 108$ billion in 2016 and are projected to decline further to $\$ 60$ billion in 2018. The deterioration of Algeria's terms of trade led to $20 \%$ nominal depreciation of the dinar since mid-2014; inflation picked up to $4.8 \%$ in 2015. Fiscal savings in the oil savings fund are likely be depleted this year, requiring more government borrowing to finance budget deficits over the medium term.

According to the Ministry of Finance, during the first 2 months of 2016, the Algerian budget deficit deteriorated to 1404 billion dinars (about $\$ 14$ billion), which in fact has increased to $240 \%$ with regard to the same period in 2015 . Tax revenues decreased to $20.2 \%$ which was affected by a fall in oil prices. Budget expenditures have risen rapidly, where it shifted from 1223 billion to 2040 billion Algerian dinars (66.9\%).

Some fiscal adjustment was achieved in 2017, but much smaller than planned. The nonhydrocarbon deficit is estimated to have declined by less than $2 \%$ of nonhydrocarbon GDP on a cash basis to $26.4 \%$ of nonhydrocarbon GDP. Overall spending was cut by about $1.3 \%$ in nominal terms, less than the $5.8 \%$ initially budgeted. The decrease in capital expenditures ( $3 \%$ in nominal terms) offset a nominal increase in current expenditures (3.8\%). Although sizeable dividends from BA (4.9\% of GDP) helped reduce the overall deficit from $13.5 \%$ of GDP to $8.8 \%$ of GDP, the government faced financing difficulties following the depletion of savings in the oil stabilization fund (FRR) early in the year and incurred domestic payment arrears. Since November, it has resorted to central bank borrowing to finance the deficit (equivalent to 3\% of GDP for 2017). BA financing was also used to buy back public enterprise debt and finance the National Investment Fund (FNI), for an equivalent of $8.6 \%$ of GDP. With the depletion of fiscal savings

\footnotetext{
${ }^{18}$ Algeria created an oil stabilization fund (Fonds de Regulation des Recettes, or FRR) in 2000 to insulate the Algerian economy from volatility in hydrocarbon prices. There is a saving rule that stipulates that oil revenue is saved into the FRR above the oil price threshold of US\$37 per barrel. The FRR was depleted in February 2017.

19 Public entities include: Algérie Poste, local governments, and other public institutions. The government has an obligation to replenish the deposits used to finance the budget deficit, although there is no set timeframe.

20 The central government also finances part of its deficit by using deposits from other public entities in the single treasury account "circuit du Trésor". The government does not include such financing as public debt although, in essence, it incurs a liability.
} 


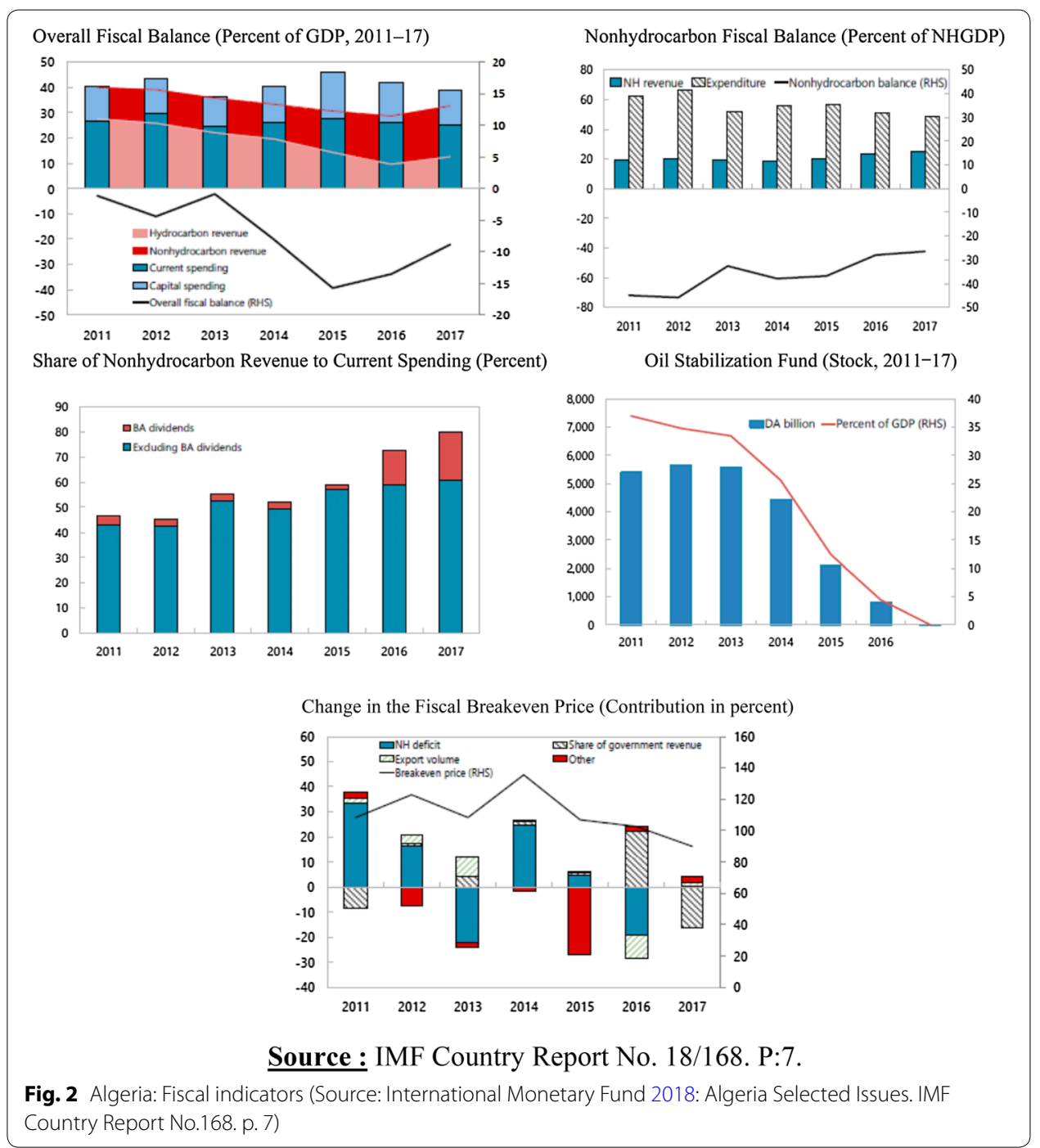

and the materialization of fiscal risks (including support to public enterprises), central government debt has increased significantly since 2016, but remains relatively low at $27 \%$ of GDP at the end-2017. The breakeven oil price continued to decline in 2017, but remained above market prices.

As a result of the rise in oil prices which exceeded \$ 60 a barrel as of November 2017, the 2018 budget includes a significant increase in spending, which will result in a deficit more than 6\% of GDP higher than originally planned under the 2017-2019 MTBF. Capital expenditures would increase by $21.2 \%$ in nominal terms from 2017, including repaying arrears, and current expenditures by $6.9 \%$, including a significant transfer to the National Social Insurance Fund. The wage bill is kept virtually flat in nominal terms. The government intends to resume consolidation in 2019, with sharp cuts in spending, and to restore fiscal balance by 2022 . 


\section{Empirical literature}

In the last decade, several empirical studies on debt sustainability have gained extreme importance after the latest financial and debt crisis worldwide. However, Empirical tests on sustainability do not provide a consensus on this issue because results vary with the theoretical framework, the sample period, the specification of the transversality condition, and the econometric methodology used.

Three evidence-based frameworks have been used in the empirical literature. The first rests mainly on testing stationarity of the various fiscal variables (government deficit or debt), while the second employs cointegration techniques and explores the existence of a long-run equilibrium relationship between the fiscal variables of interest. ${ }^{21}$ And the third measure uses the feedback from debt to deficit. ${ }^{22}$

Under the first framework, if the deficit series is non-stationarity, then it means that it grows without bound over time, which means that subsequent debt will also grow without bound rendering fiscal policy unsustainable. This will also violate Present Value Budget Constraint (PVBC) and the No-Ponzi-Game (NPG) constraints. A stationary deficit means that the series is reverting to a certain mean overtime being in general close zero. If that were the case, then obviously fiscal policy and debt would be sustainable, since deficits will be under control, oscillating between small deficits and surpluses overtime.

In this context, various empirical studies on developed economies were initiated by the paper of Hamilton and Flavin (1986). Using yearly data for the US, covering the period 1962-1984, they tested the validity of the PVBC, or equivalently the NPG condition, or the budget constraint. In their study, if the government deficit and debt series are stationary, then debt is sustainable which is the case for the US sample used. Using also yearly data for the US economy over a larger sample covering respectively the periods: 1890-1983 and 1960-1984, Trehan and Walsh (1988) looked at the stationarity of public deficits and debt, and concluded that since they were stationary for both sample periods, then debt is sustainable. However, Kremers (1988) and Wilcox (1989) show that Hamilton and Flavin's unit-root tests suffer from the problem of serial correlation in residuals, once serial correlation is accounted for, the findings of stationarity are reversed, and the US primary surplus and debt become non-stationary.

However, these results may be biased since they do not take into account the possibility of regime shifts in fiscal policy. Another reason is that public debt and deficits present a nonlinear behavior which is not taken into account in previous studies. Most of the studies that tested for the presence of these shifts consider models with structural breaks or threshold effects in the behavior of public debt and deficits, where the breakpoints are either chosen arbitrarily (e.g., they are exogenous) or are endogenously determined.

In this regard, Davig (2005) uses a Markov-switching time series model to analyze the behavior of the discounted US federal debt. The author uses an extended version of Hamilton and Flavin (1986) and Wilcox (1989) data and identifies two fiscal regimes: in

\footnotetext{
${ }^{21}$ For details, see: Haug (1991), Smith and Zin (1991), Hakkio and Rush (1991), Ahmed and Rogers (1995), Quintos (1995), Martin (2000). Other studies using a cointegration framework to test the validity of the IBC in Europe, include Bravo and Silvestre (2002) and Afonso and Rault (2010) for eleven and ten EU countries, respectively. Both studies reach mixed results with regard to the validity of the IBC in their sample countries.

22 For details, see: Wickens and Uctum (1993), Bohn (1998), Feve and Henin (2000), Uctum et al. (2006).
} 
the first one, the discounted federal debt is expanding, whereas, it is collapsing in the second one. He concludes that although the expanding regime is not sustainable, it does not pose a threat to the long-run sustainability of the discounted US federal debt.

Again, Huang (2006) examines the Taiwan public debt sustainability for the period of 1967:1 to 2006:4 using the public debt as a percentage of GDP. The results of linearity tests suggest that the debt-GDP ratio has nonlinear characteristics. But when applying a nonlinear model, the result of model selection shows that the debt-GDP ratio is better represented by the ESTAR than LSTAR. In addition, the estimation results of linear and nonlinear models indicate that nonlinear modeling could be used to calculate the adjustment behaviors and better than the linear modeling. However, there is no strong evidence of nonlinear mean reversion in the debt-GDP ratio. There is no strong evidence to support the Taiwan public debt sustainability. Huang (2014) re-examine this issue, but he used an unrestricted two-regime threshold autoregressive (TAR) model with an autoregressive unit root. The empirical results show that Taiwan's public debt appears as a nonlinear series and is stationary in regime 1 but not in regime 2 . This result implies that while Taiwan's public debt was mostly sustainable over the 1996 to 2013 period examined in the study, it may no longer be sustainable in the most recent 2 years as the public debt ratio has increased cumulatively to $3.618 \%$.

On the other hand, Arghyrou and Luintel (2007) re-examine this issue on Greece, Ireland, Italy and the Netherlands by utilizing a new empirical approach and extended data sets. Issues of structural shifts and nonlinear fiscal adjustment are tackled. They find that (i) the fiscal path of these countries went through multiple shifts; (ii) most of these shifts correspond to important policy changes and/or external shocks; (iii) the government finances of all four countries satisfy the IBC across different time horizons; and (iv) fiscal disequilibrium adjusts nonlinearly. They also find a clear positive Maastricht effect on the IBCs of all countries.

Similarly, Chortareas et al's study (2008) analyzes the sustainability of government debt for Latin American and Caribbean countries employing unit-root tests that incorporate a nonlinear alternative in the form of an Exponential Smooth Transition Autoregressive (ESTAR) and self-exciting threshold autoregressive (SETAR) model with three regimes. They show that, in general support for sustainability substantially improves when nonlinear mean reversion is taken into account. They also find that the results obtained from applying various tests with nonlinear alternatives, although broadly consistent, are not identical. This suggests that reliance on a single unit-root test for assessing fiscal policy sustainability may be misleading.

Using Brazilian data, Lima et al. (2008) investigate fiscal sustainability by using a quantile autoregression (QAR) model. They propose a novel methodology to separate periods of nonstationarity from stationary ones, which allows us to identify various trajectories of public debt that are compatible with fiscal sustainability. They use such trajectories to construct a debt ceiling, that is, the largest value of public debt that does not jeopardize long-run fiscal sustainability. They make out-of-sample forecast of such a ceiling and show how it could be used by Policy makers interested in keeping the public debt on a sustainable path.

Furthermore, Baharumshah and Lau (2010) examine the mean reverting behaviour of fiscal deficit by analysing the fiscal position of 24 developing countries. Using annual 
data over the period 1970-2003 and the series-specific panel unit-root test developed by Breuer et al. (2001), they found the budget process for most developing countries that fails to satisfy the strong-form sustainability condition. Further investigation shows the budget process for a majority of the countries is on a sustainable path (weak form) when a one-time, structural break is allowed in the model.

Moreover, Gabriel and Sangduan (2011) propose a Markov-switching cointegration approach to assess the long-run fiscal sustainability (switch between stationarity and non-stationarity, or switches between 'strong' and 'weak' sustainability). Their method allows us simultaneously test for cointegration in the presence of significant fiscal policy changes; assess the type of fiscal regime that a country experienced at a given period; and analyze the timing of the transition between the estimated regime types.

Fincke and Greiner (2011) Testing for sustainability of public debt by analyzing how the primary surplus reacts to variations in debt, as suggested by Bohn (1998). They apply that test to some countries of the euro area, including Greece, Ireland, Italy, Portugal, and Spain (GIIPS) countries, where they allow for a time-varying reaction coefficient. They conclude that most economies are characterized by sustainable debt policies with the exception of Greece and possibly Italy. While Greece has clearly pursued an unsustainable debt policy, no clear-cut result can be obtained for Italy. For the latter country, the outcome crucially depends on the time period under consideration.

Similarly, using long historical data on the debt-to-GDP ratios of the GIIPS, Legrenzi and Milas (2012) extend previous literature by evaluating debt sustainability based on a number of nonlinear models with fixed and time-varying thresholds. They provide evidence that fiscal sustainability occurs when debt gets "too high" relative to a threshold which is not necessarily fixed but varies with the level of debt relative to its recent history and/or the occurrence of a financial crisis.

Jawadi and Sousa (2013) investigate the short-term dynamics for public debts in the US and the UK over a period of more than four decades. They check for structural changes in the data and assess nonlinearity and regime-switching hypotheses using several linearity tests. Their findings point to multiple structural breaks due to economic downturns, oil shocks, and financial and political instabilities. They also identify different regimes for which the adjustment is asymmetric and nonlinear, in particular, since 2003 and around the Great Recession.

Aldama (2014) proposes to extend this analysis to a Markov-switching fiscal rule in which government switches between two regimes: locally unsustainable and locally sustainable. Therefore, he derives a modified Model-Based Sustainability test which introduces explicitly regime-switching. He shows that a globally "responsible" or sustainable fiscal policy can be periodically unsustainable, as long as it verifies some intuitive conditions depending not only on fiscal reaction parameters but also on average duration of each regime such that sustainable regimes balance unsustainable regimes in the long run.

Shiamptanis (2015) examines how a nonlinear fiscal policy rule affects the possibility of future insolvency in a small open economy (Canada). He finds that the criteria for a nonlinear fiscal rule to eliminate explosive behavior should be tighter than the ones proposed by Bohn (1998). Also, a country that adopts a nonlinear fiscal rule could substantially reduce the probability of a solvency crisis, and the adoption of a nonlinear 
fiscal rule allows a country to reduce the possibility of insolvency without large initial responsiveness.

Piergallini and Postigliola (2013) investigate the sustainability of Italy's public finances from 1862 to 2012 adopting a nonlinear perspective. Specifically, they employ the smooth transition regression (STAR) approach to explore the scope for nonlinear fiscal adjustments of primary surpluses in response to the accumulation of debt. Their results show that the hypothesis of nonlinearity in the surplus-debt relationship significantly outperforms the hypothesis of linearity. Also, there exists a threshold level in the debtGDP ratio, equal to $111 \%$, above which Italian fiscal policy makers are concerned with corrective actions to avoid insolvency. As well, the robustly positive reaction of primary surpluses to debt beyond the trigger point ensures fiscal sustainability.

Cassou et al. (2017) empirically investigate US fiscal policy sustainability and cyclicality in an empirical structure that allows fiscal policy responses to exhibit asymmetric behavior. Most importantly, they compare two economic data periods-the short sample, and the long sample-and show that the long sample is sufficiently different from the short sample in that simple linear models are not appropriate for modeling fiscal policy and that the switching models used here are extremely important. For the short sample, fiscal policy is both symmetric and sustainable, confirming results by Bohn (1998). However, over the full sample, fiscal policy is sustainable during good economic times only for the Markov-switching models, while all the other specifications (linear and threshold models) studied in this paper do not support the sustainability hypothesis.

The approach to test for fiscal sustainability using fiscal reaction functions was criticized by Ghosh et al. (2013). In this regard, Mackiewicz-Lyziak and Lyziak (2019) develop a new test for fiscal sustainability and propose a synthetic fiscal sustainability indicator. Conventional tests based on fiscal reaction functions assume a constant real interest rate. However, many empirical studies find evidence on a positive response of long-term rates to sovereign debt levels. They take this evidence into account and endogenize the long-term real interest rate in testing fiscal sustainability. They apply the new test for the European economies. They find that considering the response of interest rate to debt may change the assessment of fiscal sustainability. More specifically, their results indicate that fiscal sustainability is at risk in a number of European Union economies, even if the results of traditional approaches suggest sustainable fiscal policy.

Irungu et al. (2019) investigate the nature of fiscal policy regime in Kenya and the extent to which fiscal policy is sustainable in the long run taking into account periodic regime shifts. Markov-switching models were used to endogenously determine fiscal policy regimes. Regime-switching tests were used to test whether No-Ponzi game condition and debt-stabilizing condition were met. The results established that regime-switching model was suitable in explaining regime-sustainable and -unsustainable cycles. An investigation of fiscal policy regimes established that both sustainable and unsustainable regimes were dominant, and each lasted for an average of 4 years. Regime-switching tests for long-run sustainability suggested that the No-Ponzi game condition weakly holds in the Kenyan economy. Regime-based sensitivity analysis indicated that the persistence of unsustainability regime for more than 4 years could threaten long-run fiscal sustainability. 


\section{Methodology}

The typical empirical approach of fiscal policy sustainability represents an examination of the government's debt stationarity or deficit. However, the traditional stationarity tests used by this approach are inadequate when the fiscal variables exhibit a threshold behavior, which biases results to rejecting unit roots.

This empirical study uses the budget balance -GDP ratio to examine the fiscal sustainability. Smooth transition autoregressive (STAR) models are of fundamental importance when the main purpose is to analyze the issue of long-term fiscal sustainability. Such models, indeed, enable one to account for the possible occurrence of a delayed mean reversion mechanism. We will use STAR models in order to detect the nonlinear behavior of fiscal policy. Our goal is to find a threshold value of transition variable that require decision-makers to make an adjustment in Algerian fiscal policy, as well as calculate the speed transition from one regime to another, and estimate the transition function. Then, we examine the persistence of shocks in the variable which will treat them by means of unit-root tests that account for the possibility of nonlinearities and structural changes.

\subsection{Model specification}

In time series analysis, there are many nonlinear time series models in the literature. Before introducing the Smooth Transition Autoregressive model, we will first look at a simple one: Threshold Autoregressive (TAR) model. This model can be considered as an extension of autoregressive models, allowing for the parameters changing in the model according to the value of an exogenous threshold variable $S_{t-d}$. If it is substituted by the past value of $y$, which means $S_{t-d}=y_{t-d}$, then we call it Self-Exciting Threshold Autoregressive model (SETAR). Some simple cases are shown as follows:

TAR model:

$$
Y_{t}=\left\{\begin{array}{ccc}
\varphi_{10}+\varphi_{11} y_{t-1}+\varepsilon_{1 t} & \text { if } \quad s_{t-d} \leq c \\
\varphi_{20}+\varphi_{21} y_{t-1}+\varepsilon_{2 t} & \text { if } & s_{t-d}>c
\end{array} .\right.
$$

SETAR model:

$$
Y_{t}=\left\{\begin{array}{ccc}
\varphi_{10}+\varphi_{11} y_{t-1}+\varepsilon_{1 t} & \text { if } \quad y_{t-1} \geq c \\
\varphi_{20}+\varphi_{21} y_{t-1}+\varepsilon_{2 t} & \text { if } \quad y_{t-1}<c
\end{array}\right.
$$

where $d$ is the delay parameter, triggering the changes between two different regimes. These models can be applied to the time series data which has a regime- switching behavior. However, the threshold value in the model here is discontinuous. ${ }^{23}$ By replacing the threshold value with a smooth transition function, the TAR model could be generalized to the Smooth Transition Autoregressive (STAR) model. Now the observations $y_{t}$ switch between two regimes smoothly in the sense that the dynamics of $y_{t}$ may be determined by both regimes, with one regime having more impacts in some times, and the other regime having more impacts in some other times. Another interpretation is that STAR models actually allow for a "continuum" of regimes, each associated with a

\footnotetext{
${ }^{23}$ Although the TAR models allow detects the nonlinearity and was able to give a good economic explanation through a some mechanism and observable transition variable, but it suffers from some shortcomings, most notably, the transition variable value gets away from the threshold and does not change the explanatory variable parameters in a single system, but these transactions are affected only when the transition variable is larger or smaller than the threshold value.
} 
different value of $F\left(s_{t}\right)$. The smooth transition model is theoretically more appealing than the simple TAR models that impose an abrupt switch in parameter values. An abrupt switch only happens if all agents act simultaneously. ${ }^{24}$

The smooth transition autoregressive model for a univariate time series of order $p$ is defined as follows:

$$
Y_{t}=\left(\phi_{10}+\sum_{j=1}^{p_{1}} \phi_{1 j} x_{t-j}\right)\left[1-F\left(S_{t} ; \gamma, c\right)\right]+\left(\phi_{20}+\sum_{j=1}^{p_{2}} \phi_{2 j} x_{t-j}\right) F\left(S_{t} ; \gamma, c\right)+\varepsilon_{t}, \quad \gamma>0 .
$$

$x_{t}$ is the vector of explanatory variables containing lags of the endogenous variable and the exogenous variables (or the time trend). The transition variable $s_{t}$ may be a delayed value of $y$ as in SETAR models, but also an exogenous variable or function of exogenous variables. $c$ is the threshold value, and $\gamma$ determines the speed and smoothness of the transition. $F$ stands for a continuous transition function usually bounded between 0 and 1 . Because of this property, not only can the two extreme states be explained by the model, but also a continuum of states that lie between those two extremes.

The most popular functional forms of the transition function specified by Teräsvirta (1994) are as follows:

Logistic transition function:

$$
L\left(S_{t} ; \gamma, c\right)=\left[1+\exp \left(-\gamma\left(s_{t}-c\right)\right)\right]^{-1} .
$$

The resulting model is referred to as logistic STAR or LSTAR model,

Exponential transition function:

$$
E\left(S_{t} ; \gamma, c\right)=\left[1-\exp \left(-\gamma\left(s_{t}-c\right)^{2}\right)\right]
$$

The resulting model is referred to as exponential STAR or ESTAR model.

If $\gamma$ is small, both transition functions switch between 0 and 1 very smoothly and slowly; if $\gamma$ is large, both transition functions switch between 0 and 1 more quickly. As $\gamma \rightarrow \infty$, both transition functions become binary. However, the logistic function approaches the indicator function $F\left(s_{\mathrm{t}}>c\right)$ and the LSTAR model reduces to a TAR model; while the exponential function approaches the indicator function $F\left(s_{t}=c\right)$ and the model does not nest the TAR model as a special case.

The logistic function is monotonic and the LSTAR model switches between two regimes smoothly depending on how much the transition variable $s_{t}$ is smaller than or greater than the threshold $c$. The exponential function is symmetrical, and the ESTAR model switches between two regimes smoothly depending on how far the

\footnotetext{
${ }^{24}$ Change at the aggregate level will be adequately represented by a STAR model if the economy is made up of a large number of individuals or companies, each of which changes abruptly the regime but at different dates. This non-simultaneity of individual behavior can indeed be justified by the fact that some individual agents or institutional agents can benefit from anticipating government action and begin their transition before the change of economic policy, while information delay costs or adjustments may lead other agents to react with a delay to the action of the authorities. This justification can be expanded to include even some cases where the reactions of the individual agents are by themselves, gradually and to varying degrees, caused by agent's behavioral myopia, which may be due to the presence of the costs of the transition, or getting stuck to habits. Added to this is the uncertainty factor which imparts gradual property to the transition, since the economic agents do not trust in the continuation of the new economic policies, and therefore do not adjust their behavior immediately with the new system, but converge and adapt gradually with the agent after getting more information and skills across time.
} 
transition variable $s_{t}$ is from the threshold $c$. For the LSTAR model, both the distance between $s_{t}$ and $c$ and its sign matter; for the ESTAR model, only the distance between $s_{t}$ and $c$ matters, but not the sign. Since $L\left(S_{t} ; \gamma, c\right)$ is not symmetric about $c$, the LSTAR is capable of generating the symmetric short-run dynamics in two forms.

\subsection{Test for STAR nonlinearity}

Testing for the existence of STAR-type nonlinearity is usually the first step toward building a STAR model. However, just like the test for threshold type nonlinearity, tests for the null hypothesis of a simple AR model against the alternative of a STAR model have nonstandard asymptotic distributions, because some parameters in the STAR model are not identified under the null hypothesis, such as the AR coefficients in the second regime, the transition parameter $\gamma$ and the threshold $c$.

To avoid complicated issues caused by the unidentified STAR model parameters under the null hypothesis of a linear AR model, Luukkonen et al. (1988) propose to replace the transition function $F\left(s_{\mathrm{t}} ; \gamma, c\right)$ by a suitable Taylor series approximation around $\gamma=0$. It turns out that if the transition function $F\left(s_{\mathrm{t}} ; \gamma, c\right)$ in the LSTAR model is replaced by its third order Taylor series approximation, the LSTAR model can be written as:

$$
T_{3}\left(S_{t} ; \gamma, c\right)=\frac{1}{4} \gamma\left(S_{t}-c\right)+\frac{1}{48} \gamma^{3}\left(S_{t}-c\right)^{3} .
$$

Using this approximation yields the auxiliary model:

$$
Y_{t}=\beta_{0}+\beta_{1} X_{t}+\beta_{2} X_{t} s_{t}+\beta_{3} X_{t} s_{t}^{2}+\beta_{4} X_{t} s_{t}^{3}+u_{t} .
$$

Now testing the null hypothesis of a linear AR model against a nonlinear STAR model is equivalent to testing the null hypothesis $H_{0}: \beta_{j}=0$ for $j=1,2,3,4$ in the above auxiliary regressions, which is a conventional Lagrange multiplier $(L M)$ test with an asymptotic $\chi^{2}$ distribution with 3p degrees of freedom asymptotically. Teräsvirta (1994) suggests that the LM-type test can also be used to select the appropriate transition variable in the STAR model. The statistic is computed for several candidate transition variables and the one for which the $p$ value of the test is the smallest, and is selected as the true transition variable.

\subsection{Choosing between LSTAR and ESTAR models}

After rejecting the null hypothesis of linearity, the next step is to choose between LSTAR and ESTAR models by a sequence of nested tests within (14) as followed:

Teste $\mathrm{F}_{4:}:\left\{\begin{array}{l}H_{01}: \beta_{4}=0 \\ H_{11}: \beta_{4} \neq 0\end{array}\right.$

Teste $\mathrm{F}_{3:}\left\{\begin{array}{l}H_{02}: \beta_{3}=0 / \beta_{4}=0 \\ H_{12}: \beta_{3} \neq 0 / \beta_{4}=0\end{array}\right.$

Teste $\mathrm{F}_{2:}:\left\{\begin{array}{l}H_{03}: \beta_{2}=0 / \beta_{3}=\beta_{4}=0 \\ H_{13}: \beta_{2} \neq 0 / \beta_{3}=\beta_{4}=0\end{array}\right.$ 
The decision rules of choosing between LSTAR and ESTAR models are suggested by Teräsvirta (1994): First, we may check directly the test of $H_{01}$, if the null hypothesis is rejected, this may be interpreted as a favor of the LSTAR model. If we are not able to reject $H_{02}$, this can be supportive for the LSTAR model, which will be supported by rejecting after accepting as well. Then the rules will be the other way around for picking the ESTAR model. We can also choose by comparing the significance level of the three F-tests, if the $p$ value of the test of $H_{02}$ is the smallest among the three, select an ESTAR model; if not, then choose a LSTAR model.

\subsection{Estimation of STAR models}

Once the transition variable $s_{\mathrm{t}}$ and the transition function $F\left(s_{t} ; \gamma, c\right)$ have been selected, the next stage in the modelling cycle is the estimation of the parameters in the STAR model. Estimation of the parameters in the STAR model is a relatively straightforward application of nonlinear least squares (NLS) - that is, the parameters $\theta=\left(\phi_{1 j}, \phi_{2 j}, \gamma, c\right)$ can be estimated as: $\widehat{\theta}=\arg \min _{\theta} Q_{n}(\theta)=\arg \min _{\theta} \sum_{t=1}^{n}\left[Y_{t}-F\left(X_{t} ; \theta\right)\right]^{2}$ where $F\left(\theta, X_{t}\right)$ is the skeleton of the model, that is, $F\left(\theta, X_{t}\right)=\phi_{1 j} X_{t-j}+\phi_{2 j} X_{t-j} F\left(s_{t} ; \gamma, c\right)$. Under the additional assumption that the errors $\varepsilon_{t}$ are normally distributed, NLS is equivalent to maximum likelihood. Otherwise, the NLS estimates can be interpreted as quasi-maximum likelihood estimates (Franses and van Dijk 2003, p. 90). The estimation can be performed using any conventional nonlinear optimization procedure. Issues that deserve particular attention are the choice of starting values for the optimization algorithm, focusing on the sum of squares function and estimation of the smoothness parameter $\gamma$ in the transition function. It immediately follows that sensible starting value for the nonlinear optimization can be easy obtained by a twodimensional grid search over $\gamma$ and $c$. Therefore, a grid search is performed to pin down the starting values for the estimation, which minimize the residuals' sum of squared.

\subsection{STAR unit-root tests}

We consider whether $Y_{t}$ or its discounted version is stationary using unit-root tests that incorporate a nonlinear alternative. The first test, due to Kapetanios et al. (2003) henceforth KSS and Eklund (2003), considers the null hypothesis of a unit root against the alternative of a STAR model in a context similar to DF test. ${ }^{25}$

The nonlinear form of an ADF equation corresponding to the class of STAR models is

$$
\Delta Y_{t}=\rho_{1} Y_{t-1}+\rho_{2} Y_{t-1} F\left(s_{t} ; \gamma, c\right)+\varepsilon_{t} .
$$

KSS further impose the assumption that $\rho_{1}=0$. The reason is that, in some economic contexts, it is reasonable to assume that the variable displays a mean reverting behavior toward an attractor when it is sufficiently far away from it, but a random walk representation in the neighborhood of the attractor. In this case, we have that:

$$
\Delta Y_{t}=\rho_{2} Y_{t-1}\left[1-\exp \left(-\gamma Y_{t-1}^{2}\right)\right]+\varepsilon_{t}
$$

\footnotetext{
${ }^{25}$ We refer to this test as the nonlinear augmented Dickey-Fuller (NLADF) test.
} 
The test for the joint null hypothesis of linearity and a unit root can be achieved by testing $H_{0}: \gamma=0$ against $H_{1}: \gamma>0$. Using a first order Taylor series approximation to (15), we can obtain: ${ }^{26}$

$$
\Delta Y_{t}=\delta Y_{t-1}^{3}+\text { error. }
$$

The unit-root test is based on the $\mathrm{t}$-statistic for the null $H_{0}: \delta=0$ against the alternative $H_{1}: \delta<0$ from the OLS estimate of $\delta$. The asymptotic distribution of this test $t_{N L}$ $\left(\mathrm{NLADF}=\frac{\hat{\delta}}{\text { s.e. }(\hat{\delta})}\right)$ is nonstandard, and KSS derive it and provide asymptotic critical values. In the presence of constants and trends, the data are first detrended/demeaned. ${ }^{27}$

Apart from Sollis (2009), Kruse (2011) present invaluable contributions to the testing of unit roots considering nonlinearity. Hepsag (2019) developed a new unit-root testing procedure which considers jointly for structural breaks and nonlinear adjustment. In their proposed test, structural breaks are modeled by means of a logistic smooth transition function that allows in the intercept, in the intercept under a fixed slope and in the intercept and slope terms. ${ }^{28}$ Nonlinear adjustment is modeled by means of an STAR model as suggested by Kruse (2011).

\subsection{Unit-root tests allowing for structural breaks}

The previous nonlinear unit-root test allows for structural change in a smooth process. However, a superficial visual inspection of the budget balance or other macroeconomic series suggests the presence of potential structural breaks which reflect shocks rather than smooth change. For example, an economic series that conforms to a stationary process around a fixed mean, which undergoes a one-time shift, will appear to conform to a nonstationary process, unless one incorporates the shift in the mean. Following the seminal work of Perron (1989), we recognize that the presence of structural change can substantially reduce the power of unit-root tests. Zivot and Andrews (1992) propose a unit-root test that allows for an endogenous structural break. ${ }^{29}$ Lumsdaine and Papell (1997) extended the endogenous break methodology to allow for two endogenous breaks in the trend function..$^{30}$ They find more evidence against the unit-root hypothesis than Zivot and Andrews (1992), but less evidence than Perron (1989). Lee and Strazicich (2003a) propose a one-break Lagrange multiplier (LM) unit-root test ${ }^{31}$ as an alternative to the Zivot and Andrews (1992) test, while Lee and Strazicich (2003b) suggest a

\footnotetext{
${ }^{26}$ Hence, Sollis (2009) proposes a KSS-type test, which distinguishes between asymmetric or symmetric effects under the alternative hypothesis, i.e., the speed of mean reversion will be different depending on the sign of the shock and not only its size. He proposes to test for unit roots in this nonlinear framework using the auxiliary equation: $\Delta Y_{t}=\beta_{1} Y_{t-1}^{3}+\beta_{2} Y_{t-1}^{4}+$ error

The null hypothesis of symmetric STAR versus the alternative of asymmetric STAR.

27 Case 1, Case 2 and Case 3 refer to the underlying model with the raw data (zero mean), the de-meaned data (data has nonzero mean) and the de-trended data (nonzero linear trend), respectively.

${ }^{28}$ Model A: $y_{t}$ is stationary around a mean which changes from the initial value $\alpha_{1}$ to the final value $\alpha_{1}+\alpha_{2}$; Model B: is similar to Model A, with the intercept changing from $\alpha 1$ to $\alpha_{1}{ }^{i}+\alpha_{2}$, but it allows for a fixed slope term; Model C: in addition to the change in intercept from $\alpha 1$ to $\alpha_{1} \eta+\alpha_{2}$, the slope also changes contemporaneously

29 Model A: allows for a one-time change in the intercept of the trend function;

Model B: changes in the slope of the trend function;

Model C: combines changes in the level and the slope of the trend function.

${ }^{30}$ Model CC: allows for two breaks in both the intercept and the slope of the trend function; Model AA: allows for two breaks in the intercept, but not in the slope of the trend function;

Model CA: allows for two breaks in the intercept and one break in the slope of the trend function.

31 Model A: is known as the "crash" model, and allows for a one-time change in intercept; Model C: allows for a shift in intercept and change in trend slope.
} 
Table 1 Descriptive statistics of the variables used

\begin{tabular}{lccc}
\hline & $\boldsymbol{D}$ & $\boldsymbol{G}$ & $\mathbf{O}$ \\
\hline Mean & 1.627792 & 31.97861 & 30.74567 \\
Median & 0.826706 & 30.47211 & 20.06634 \\
Maximum & 19.81400 & 46.44730 & 114.9947 \\
Minimum & -15.31474 & 19.57048 & 2.910000 \\
Std. dev. & 7.527109 & 6.617537 & 29.41362 \\
Skewness & 0.045905 & 0.442866 & 1.480381 \\
Kurtosis & 2.395278 & 2.392584 & 4.341935 \\
Jarque-Bera & 3.382647 & 10.42934 & 95.54242 \\
Probability & 0.184276 & 0.005436 & 0.000000 \\
\hline
\end{tabular}

two-break LM unit-root test ${ }^{32}$ as a substitute for the Lumsdaine and Papell (1997) test. In contrast to the ADF test, the LM unit-root test has the advantage that it is unaffected by breaks under the null. In such situations, it is necessary to test for the possibility of a break using tests that account for these breaks. If there is a shift in the level of the DGP (data-generating process), it should be taken into account in testing for a unit root because the ADF test may be distorted if the shift is simply ignored. In doing so, we use the unit-root tests proposed by Saikkonen and Lütkepohl (2002). Therefore, a shift function may be added to the deterministic term of the DGP.

\section{Empirical results}

To ensure efficient use of the statistical tests carried in the analysis, we need a sufficient number of observations. Moreover, due to the lack of Algerian quarterly data for the study variables, we have converted the annual data to the corresponding quarterly data by using cubic spline interpolation method. ${ }^{33}$ Thus, budget balance quarterly data are employed in this study. The budget balance is measured as the ratio of central government budget balance (overall budget balance) to GDP. The use of the overall budget balance is consistent with previous studies of budget deficit sustainability. ${ }^{34}$ The data period is from the first quarter in 1963 to the first quarter in 2017 (giving 217 observations). The data is compiled from the National Office of Statistics, Ministry of Finance, WDI and IFS.

The nonlinear model for the budget balance-GDP ratio $(D)$ includes some exogenous threshold variables dictated by economic reality or economic theory, such as dependency of fiscal policy on the oil price $(\mathrm{O})$ in Algeria ${ }^{35}$; also the orientations of governments public spending $(G),{ }^{36}$ as well as lags of dependent variable [8 lags maximum (2 years) for each transition variable]. The descriptive statistics for the main variables are summarized in Table 1.

\footnotetext{
32 Model A: two level shifts; Model C: two levels and trend shifts.

33 For more details about this method, see the appendix in Chibi et al. (2014).

34 Trehan and Walsh (1988) argue that the assessment of budget sustainability should be based on the time series properties of the value of the overall budget balance, inclusive of interest payments and seignoirage revenue.

35 Crude Oil Prices quarterly data are compiled from Federal Reserve Bank of St. Louis and OPEC basket price.

36 Government public spending (\% GDP) data are gathered from the Ministry of Finance, Quandl website data.
} 
Table 2 Testing linearity against STR and model selection

\begin{tabular}{|c|c|c|c|c|c|}
\hline $\begin{array}{l}\text { Transition } \\
\text { variable }\end{array}$ & $F$ & $F 4$ & $F 3$ & $F 2$ & Suggested model \\
\hline$D(t-1)$ & $1.5619 \mathrm{e}-02$ & $4.5449 \mathrm{e}-02$ & $1.5936 \mathrm{e}-01$ & $1.2821 \mathrm{e}-01$ & LSTR1 \\
\hline$D(t-2)$ & $2.3193 e-01$ & $2.4984 \mathrm{e}-01$ & $3.6338 \mathrm{e}-01$ & $3.5453 e-01$ & Linear \\
\hline$D(t-3)$ & $7.2452 e-01$ & $6.7605 e-01$ & $6.3017 \mathrm{e}-01$ & $4.9937 \mathrm{e}-01$ & Linear \\
\hline$D(t-4)$ & $8.3556 \mathrm{e}-01$ & $7.8066 \mathrm{e}-01$ & $8.4043 e-01$ & $3.6497 \mathrm{e}-01$ & Linear \\
\hline$D(t-5)$ & $7.7999 \mathrm{e}-01$ & $8.0792 \mathrm{e}-01$ & $9.7320 e-01$ & $6.9631 e-02$ & Linear \\
\hline$D(t-6)$ & $7.4431 \mathrm{e}-03$ & 4.3397e-01 & $8.2779 \mathrm{e}-01$ & $2.5385 e-03$ & Linear \\
\hline$D(t-7)$ & $1.4506 \mathrm{e}-03$ & $3.8275 \mathrm{e}-01$ & $2.4542 \mathrm{e}-01$ & $1.7514 \mathrm{e}-04$ & LSTR1 \\
\hline$D(t-8)$ & $1.2869 \mathrm{e}-01$ & $2.2744 \mathrm{e}-01$ & $5.8048 \mathrm{e}-02$ & $4.6705 e-04$ & LSTR1 \\
\hline$G(t)$ & $\mathrm{NaN}$ & $\mathrm{NaN}$ & $1.1608 \mathrm{e}-01$ & $1.8470 \mathrm{e}-06$ & Linear \\
\hline$O(t)$ & $7.9259 e-1$ & $5.5309 e-02$ & $2.6174 \mathrm{e}-06$ & $5.2143 e-07$ & LSTR1 \\
\hline$G(t-1)$ & $\mathrm{NaN}$ & $\mathrm{NaN}$ & $4.7578 \mathrm{e}-01$ & $1.7889 \mathrm{e}-05$ & Linear \\
\hline$O(t-1)$ & $4.3668 \mathrm{e}-0$ & $1.1413 \mathrm{e}-01$ & $4.3676 \mathrm{e}-05$ & $3.3501 \mathrm{e}-08$ & LSTR1 \\
\hline$G(t-2)$ & $\mathrm{NaN}$ & $\mathrm{NaN}$ & $3.5836 \mathrm{e}-01$ & $5.3124 \mathrm{e}-05$ & Linear \\
\hline$O(t-2)$ & $1.6179 \mathrm{e}-09$ & $2.7641 e-02$ & $4.2262 e-04$ & $9.5567 e-09$ & LSTR1 \\
\hline$G(t-3)$ & $\mathrm{NaN}$ & $\mathrm{NaN}$ & $2.2894 \mathrm{e}-01$ & $1.3343 e-04$ & Linear \\
\hline$O(t-3)$ & $1.6062 \mathrm{e}-09$ & $3.3229 \mathrm{e}-03$ & $6.1874 \mathrm{e}-03$ & $1.2838 \mathrm{e}-08$ & LSTR1 \\
\hline$G(t-4)$ & $\mathrm{NaN}$ & $\mathrm{NaN}$ & $1.5842 \mathrm{e}-01$ & $1.0500 \mathrm{e}-03$ & Linear \\
\hline$O(t-4)$ & $6.7021 \mathrm{e}-15$ & $3.7044 e-09$ & $3.0912 \mathrm{e}-02$ & $2.2468 \mathrm{e}-08$ & LSTR1 \\
\hline$G(t-5)$ & $7.8549 \mathrm{e}-18$ & $6.8076 \mathrm{e}-19$ & $5.1238 \mathrm{e}-01$ & $4.7040 e-03$ & LSTR1 \\
\hline$O(t-5)$ & $4.1376 \mathrm{e}-13$ & $1.5390 \mathrm{e}-07$ & $4.5120 \mathrm{e}-02$ & $1.8503 e-08$ & LSTR1 \\
\hline$G(t-6)$ & $\mathrm{NaN}$ & $\mathrm{NaN}$ & $2.8722 \mathrm{e}-01$ & $3.0059 e-03$ & Linea \\
\hline$O(t-6)$ & $6.4568 \mathrm{e}-11$ & $1.1063 e-04$ & $1.2861 \mathrm{e}-02$ & $1.1099 \mathrm{e}-08$ & LSTR1 \\
\hline$G(t-7)$ & $\mathrm{NaN}$ & $\mathrm{NaN}$ & $3.2116 \mathrm{e}-01$ & $2.2393 e-03$ & Linear \\
\hline$O(t-7)$ & $4.2884 \mathrm{e}-11$ & $2.0781 \mathrm{e}-04$ & $4.5376 \mathrm{e}-03$ & $1.1331 \mathrm{e}-08$ & LSTR1 \\
\hline$G(t-8)$ & $\mathrm{NaN}$ & $\mathrm{NaN}$ & $5.5037 \mathrm{e}-01$ & $3.3869 \mathrm{e}-03$ & Linear \\
\hline$O(t-8)^{*}$ & $9.9007 e-21$ & $9.8729 e-14$ & $2.6187 e-03$ & $2.6743 e-08$ & LSTR1 \\
\hline
\end{tabular}

The next step in the specification phase is to run the linearity test. The results are shown in Table 2.

As can be seen from Table 2, the linearity test results reject a linear model, and the selected transition variable is the eighth lag of oil price $O(t-8)$ (smallest $F$ ), with the suggested model being LSTR1 with one threshold as either F4 or F2 having the strongest rejection (The meaning of the LSTAR1 is that, there is a monotonic change of parameters through the linear to nonlinear part as a function of the eighth lag of oil price in this case). ${ }^{37}$ These results show that the budget deficit (surplus) rate can be modeled with a smooth transition regression model containing two regimes (shift in fiscal policy regime), and the nonlinear dynamic process is governed by the eighth lag of oil price. Furthermore, these results support the active deficit-and-debt management hypothesis, when there is a deviation of deficit ratio from threshold).

Therefore, a grid search (see Fig. 3) is performed to pin down the starting values for the estimation that minimizes the residuals sum of squared ${ }^{38}$ (determined by the

\footnotetext{
37 The lags from 2 to 7 provided matrix inversion problem for the $p$-values of $F$-tests.

38 The sum of squared residuals is minimized when it approximates to the true value.
} 


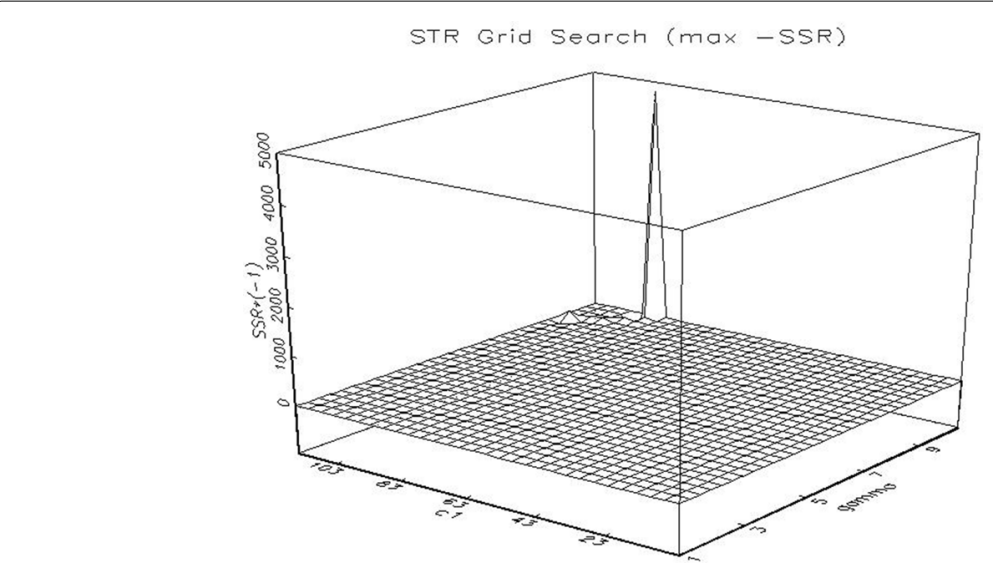

Fig. 3 STR grid search to find starting values

nonlinear optimization algorithm provided by Jmulti). The obtained starting values are $\gamma=10.0000, c=95.6698$, and SSR $=-4813.9861$.

Table 3 reports the estimated results of linear and nonlinear models for deficit-GDP ratio $D$. The STAR obtains the higher $R^{2}$, lowest estimated variance. Most of the regression coefficients were significant and in both parts at 5 and $10 \%$ levels. The threshold value was estimated at US $\$ 84.86$ per barrel, as the speed of transition (adjustment) from one regime to another was significant and estimated at $4.98 .{ }^{39}$ Accordingly, The estimated Logistic transitional function will be $L\left(S_{t} ; \gamma, c\right)=\left[1+\exp \left(-4.98\left(O_{t-8}-84.86\right)\right)\right]^{-1}$.

Figure 4 demonstrates the transition function versus the transition variable. The vertical axis is the transition function, and the horizontal axis is the transition variable. When the transition variable is less (higher) than 84.86 US Dollars per Barrel, and thus the transition function is less (higher) than 0.5 , the economy is in low-deficit (high-deficit) regime.

Results of linear unit-root tests (Table 4) show that the budget balance time series is not stationary because the calculated statistical values are greater than the critical values (the alternative hypothesis for the stationary can be rejected in favor of the null of a unit root). Within the nonlinear unit-root tests, since the calculated statistical values are greater than the critical values, we accept the null hypothesis of the unit roots and reject the alternative hypothesis for the stationary of the STAR nonlinear model. This means that the time series of the budget balance is not stationary (does not mean reverting characteristic), and therefore cannot sustain the budget deficit in Algeria over the long term. However, Sollis (2009) test shows that the effect of a shock with the same magnitude, but with different sign, will not have the same effect on the speed of adjustment toward equilibrium (rejection of the null hypothesis of symmetric STAR). This result was confirmed by using unit-root tests with structural breaks (Table 5) as we reject the alternative hypothesis for the stationary at the $1 \%$ significance level for all tests. What can be seen is that each of the break dates coincides with the beginning of the sharp rise or a drop in oil prices, which confirms the results of the selection of transition variable in

${ }^{39}$ If gamma is not significant, then the model should be interpreted as autoregressive model which is linear. 
Table 3 STR estimation

\begin{tabular}{|c|c|c|c|c|c|c|}
\hline \multirow[t]{2}{*}{ Variable } & \multicolumn{3}{|l|}{ Linear part } & \multicolumn{3}{|l|}{ Nonlinear part } \\
\hline & Estimate & $t$-stat & $p$ value & Estimate & $t$-stat & $p$-value \\
\hline CONST & 0.12239 & 1.2125 & 0.2272 & $-953,955.38$ & -0.3598 & 0.7195 \\
\hline$D(t-1)$ & 3.44095 & 56.4711 & 0 & $55,788.638$ & 5.3396 & 0 \\
\hline$D(t-2)$ & -4.85657 & -23.6939 & 0 & $-128,587.3$ & -4.4038 & 0 \\
\hline$D(t-3)$ & 3.52758 & 10.8223 & 0 & $150,274.68$ & 4.8933 & 0 \\
\hline$D(t-4)$ & -2.12355 & -5.8562 & 0 & $-59,508.708$ & -3.0057 & 0.0031 \\
\hline$D(t-5)$ & 2.89067 & 7.8714 & 0 & $14,150.225$ & 0.8531 & 0.3949 \\
\hline$D(t-6)$ & -3.60591 & -10.8688 & 0 & $-77,656.05$ & -3.0307 & 0.0029 \\
\hline$D(t-7)$ & 2.32734 & 11.4595 & 0 & $110,221.82$ & 4.5656 & 0 \\
\hline$D(t-8)$ & -0.60717 & -10.4833 & 0 & $-49,524.663$ & -2.9885 & 0.0033 \\
\hline$G(t)$ & -0.43956 & -4.2399 & 0 & 2436.6833 & 0.135 & 0.8928 \\
\hline$O(t)$ & 0.40763 & 7.17 & 0 & $-10,842.736$ & -2.7485 & 0.0067 \\
\hline$G(t-1)$ & 1.56917 & 4.2132 & 0 & $126,586.48$ & 5.456 & 0 \\
\hline$O(t-1)$ & -1.39428 & -6.655 & 0 & $26,129.101$ & 3.6575 & 0.0003 \\
\hline$G(t-2)$ & -2.31567 & -4.0119 & 0.0001 & $-274,823.19$ & -4.5956 & 0 \\
\hline$O(t-2)$ & 1.94316 & 5.9982 & 0 & $-28,718.133$ & -4.6149 & 0 \\
\hline$G(t-3)$ & 1.71933 & 3.1637 & 0.0019 & $312,310.67$ & 4.9268 & 0 \\
\hline$O(t-3)$ & -1.40125 & -1.7457 & 0 & $26,514.178$ & 5.0061 & 0 \\
\hline$G(t-4)$ & -0.86318 & -4.44 & 0.0829 & $-194,259.19$ & -3.7756 & 0.0002 \\
\hline$O(t-4)$ & 0.89336 & 2.584 & 0.0107 & $-29,810.375$ & -4.7437 & 0 \\
\hline$G(t-5)$ & 0.96113 & 1.7096 & 0.0894 & $100,486.96$ & 4.9333 & 0 \\
\hline$O(t-5)$ & -1.25769 & -2.5428 & 0.012 & $18,857.949$ & 3.3823 & 0.0009 \\
\hline$G(t-6)$ & -1.28821 & -2.1381 & 0.0341 & $-131,798.66$ & -4.1951 & 0 \\
\hline$O(t-6)$ & 1.50717 & 2.8022 & 0.0057 & -3235.5232 & -1.905 & 0.0587 \\
\hline$G(t-7)$ & -0.93333 & 2.3341 & 0.0209 & $154,937.01$ & 4.8256 & 0 \\
\hline$O(t-7)$ & 0.89894 & -2.8878 & 0.0044 & -1367.9392 & -1.9144 & 0.0574 \\
\hline$G(t-8)$ & -0.24422 & -2.3114 & 0.0221 & $-67,410.793$ & -2.1326 & 0.0346 \\
\hline$O(t-8)$ & 0.23294 & 2.8709 & 0.0047 & 941.82658 & 2.1023 & 0.02721 \\
\hline$\gamma$ & & & & 4.98625 & 3.451 & 0.0007 \\
\hline C & & & & 84.86378 & 9.8484 & 0 \\
\hline $\mathrm{AIC}:$ & $-4.2198 e+00$ & & & & & \\
\hline SC: & $-3.3243 e+00$ & & & & & \\
\hline HQ: & $-3.8578 e+00$ & & & & & \\
\hline$R^{2}$ & $9.9985 \mathrm{e}-01$ & & & & & \\
\hline Adjusted $R^{2}$ : & 0.9998 & & & & & \\
\hline SD of residuals: & 0.1084 & & & & & \\
\hline Variance of residuals: & 0.0118 & & & & & \\
\hline
\end{tabular}

nonlinear model. As for the 1994 period, it has coincided with the application of structural adjustment imposed on the reduction of the budget deficit..

\section{Concluding remarks}

The aim of this study is to analyze the technical basis of financial soundness and state solvency in order to provide some evidence on the sustainability of budget deficits in Algeria, especially when fiscal policy is conducted as a nonlinear process, which has been hardly treated in the extant literature. Our objective is to determine a threshold 


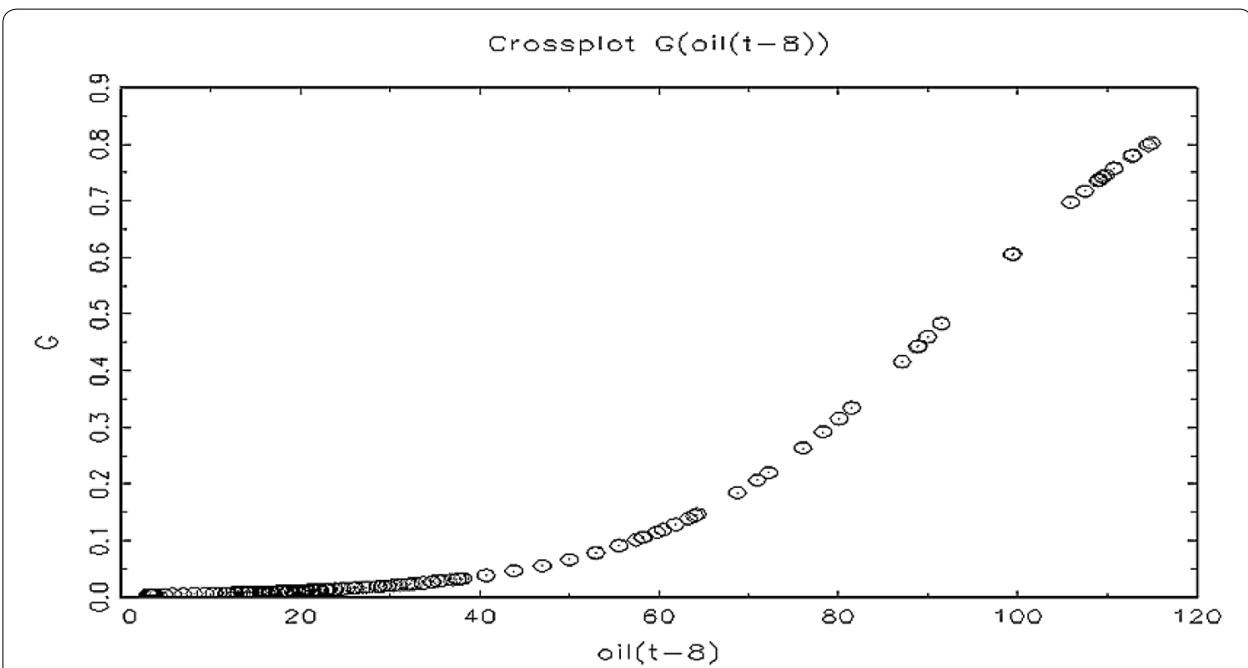

Fig. 4 The transition function vs. the transition variable

Table 4 Linear and nonlinear unit root tests

\begin{tabular}{|c|c|c|c|c|c|c|c|}
\hline \multicolumn{4}{|c|}{ Linear unit-root tests } & \multicolumn{4}{|c|}{ Nonlinear unit-root tests } \\
\hline & $\begin{array}{l}\text { Deterministic } \\
\text { components }\end{array}$ & Lags & Statistic & & $\begin{array}{l}\text { Deterministic } \\
\text { components }\end{array}$ & Lags & Statistic \\
\hline \multirow[t]{2}{*}{ ADF } & Trend and intercept & 2 & -1.2545 & KSS (2003) & Case 3 & 3 & -1.4533 \\
\hline & & & & & $t_{\mathrm{NL}}$ & & \\
\hline \multirow[t]{2}{*}{ PP } & Trend and intercept & 2 & -2.4969 & Sollis (2009) & Case 3 & 3 & 5.35697 \\
\hline & & & & & $F_{\mathrm{AE}, \mathrm{t}}$ & & \\
\hline \multirow[t]{2}{*}{ KPSS } & Trend and intercept & 2 & 0.33253 & Hepsag (2019) & Model C & 3 & 11.1976 \\
\hline & & & & & $\tau_{\text {SNLaß }}$ & & \\
\hline \multirow{2}{*}{$\begin{array}{l}\text { Ng and Perron } \\
(2001)\end{array}$} & Trend and intercept & 2 & $\mathrm{MZa}$ & $M Z t$ & MSB & MPT & \\
\hline & & & -2.0517 & -0.9224 & 0.44957 & 39.2977 & \\
\hline
\end{tabular}

ADF and PP: Critical values are: $-4.001,-3.430$ and -3.139 at $1 \%, 5 \%$ and $10 \%$ respectively

KPSS: Critical values are: $0.216,0.146$ and 0.119 at $1 \%, 5 \%$ and $10 \%$ respectively

KSS (2003): Critical values for the detrended and demeaned data are: $0.216,0.146$, and 0.119 at $1 \%, 5 \%$ and $10 \%$ respectively Sollis (2009): Critical values are: $8.531,6.463$ and 5.460 at $1 \%, 5 \%$ and $10 \%$ respectively

$\mathrm{Ng}$ and Perron (2001): Critical values at 5\% are: $-17.3000,-2.91000,0.16800,5.48000$

Hepsag (2019): Critical values are: $16.897,12.621$ and 10.749 at $1 \%, 5 \%$ and $10 \%$ respectively

See Additional file 1

value of transition variable that lead decision-makers to formulate an adjustment in Algerian fiscal policy, calculate the speed transition from one regime to another, and estimate the transition function. The findings of the empirical study evidently showed the existence of the threshold effects in the Algerian budget deficit (nonlinear behavior and shift in fiscal policy regime) in the form of a Logistic model (LSTR) containing two regimes with one threshold, and depending on the third lag in oil price. Thus, the results hold up the active deficit-and-debt management hypothesis, when there is a deviation of deficit ratio from its equilibrium. More specifically, government authorities would intervene by cutting deficits and worsening debt only when they have attained a certain threshold (US \$ 84.86 per barrel). On the other hand, nonlinear unit-root tests accept 
Table 5 Unit-root tests with structural break

\begin{tabular}{|c|c|c|c|c|c|c|c|}
\hline & & \multicolumn{6}{|c|}{ One structural break } \\
\hline & & \multicolumn{3}{|c|}{ Deterministic components } & Lags & Statistic & Break date $T B$ \\
\hline Zivot and Andrews (1992) & & \multicolumn{3}{|l|}{ Model C } & 4 & -3.86258 & 1998 Q3 \\
\hline Lee and Strazicich (2003a) & & \multicolumn{3}{|l|}{ Model C } & 7 & -3.87873 & 1976Q4 \\
\hline \multirow[t]{5}{*}{ Saikkonen and Lütkepohl (2002 } & & \multicolumn{3}{|c|}{$\begin{array}{l}\text { Shift dummy } f_{\mathrm{t}}^{(1)} \\
\text { Exponential shift } f_{\mathrm{t}}^{(2)}\end{array}$} & 2 & -1.0536 & 1974Q1 \\
\hline & & \multicolumn{3}{|c|}{$\begin{array}{l}\text { Rational shift } f_{\mathrm{t}}^{(3)} \\
\text { Model C }\end{array}$} & 2 & -1.0508 & 1974Q1 \\
\hline & & \multicolumn{3}{|l|}{ Model C } & 2 & -1.1562 & 1974Q1 \\
\hline & \multicolumn{7}{|c|}{ Two structural breaks } \\
\hline & & $\begin{array}{l}\text { rministic } \\
\text { ponents }\end{array}$ & Lags & Statistic & \multicolumn{2}{|c|}{ Break date I (TB1) } & Break date II (TB2) \\
\hline Lumsdaine and Papell (1997) & & el CC & 2 & -4.5993 & 1994 Q4 & & 2008Q2 \\
\hline Lee and Strazicich (2003b) & & el C & 7 & -4.81793 & 1976Q4 & & 1977Q2 \\
\hline \multicolumn{8}{|c|}{ Zivot and Andrews (1992): Critical values are: $-5.57,-5.08$ and -4.82 at $1 \%, 5 \%$ and $10 \%$ respectively } \\
\hline \multicolumn{8}{|c|}{ Saikkonen and Lütkepohl (2002): Critical values $(T=1000)$ are: $-3.48,-2.88$, and -2.58 at $1 \%, 5 \%$ and $10 \%$ respectively } \\
\hline \multicolumn{8}{|c|}{ Lumsdaine and Papell (1997): Critical values are: $-7.34,-6.82$ and -6.49 at $1 \%, 5 \%$ and $10 \%$ respectively } \\
\hline \multicolumn{8}{|c|}{ Lee and Strazicich (2003a): Critical values: $-5.11,-4.51$ and -4.17 at $1 \%, 5 \%$ and $10 \%$ respectively } \\
\hline \multicolumn{8}{|c|}{ Lee and Strazicich (2003b): Critical values: $-6.33,-5.71$ and -5.33 at $1 \%, 5 \%$ and $10 \%$ respectively } \\
\hline \multicolumn{8}{|c|}{ See Additional file 2} \\
\hline
\end{tabular}

the null hypothesis of the unit roots and reject the alternative hypothesis for the stationarity of the STAR nonlinear model. This means that the time series of budget balance is not stationary (not mean reverting characteristic), and therefore cannot sustain the budget deficit in Algeria over the long term. However, the effect of a shock with the same magnitude, but with distinctive sign, will have a similar effect on the speed of adjustment toward equilibrium. Moreover, the break dates coincide with the beginning of the sharp rise or a drop in oil prices, which validates the outcomes of selecting the transition variable in nonlinear model. Based on these results, the Algerian fiscal framework should consider the following aspects:

- Managing resource funds for future generations (the FRR should be transformed into a full-fledged sovereign wealth fund), and it requires to be supported by an adequate institutional arrangement (Fiscal Responsibility Law, Organic Budget Law, Extractive Industries Transparency Initiative).

- Since fiscal consolidation will unavoidably have a negative impact on growth, it should rely primarily on fiscal levers that have the smallest multipliers and be accompanied by ambitious structural reforms.

- With a significant reduction in hydrocarbon revenues, Algeria needs to mobilize more nonhydrocarbon revenues. To increase more non-hydrocarbon revenues, tax exemptions (e.g., on VAT) should be significantly reduced, excise taxes increased, and property taxes overhauled.

- Implicit and explicit subsidies should be gradually phased out and a well-targeted cash transfer system should be introduced to protect vulnerable consumers.

- Re-orientating public spending through paying more attention to the areas that encourage productivity growth and that were able to improve the efficiency of uti- 
lization of production capacity. Public investment spending should be strategically curtailed and its efficiency substantially improved. Also current expenditure should be curtailed, including by containing growth in the wage bill.

Finally, we note a limitation of our analysis. Compared to the quantiles AR approach (QAR), the nonlinear methods such as the smooth transition autoregressive (STAR), threshold autoregressive (TAR), or Markov-switching methods are not able to estimate conditional quantiles since they were originally proposed to estimate nonlinear models for conditional means (or variance). A second remark is that reliance on single types of unit-root test when assessing fiscal policy sustainability may turn out to be misleading, and therefore an array of tests should be used in order to obtain confident results. Of course, a comprehensive assessment of fiscal policy sustainability would require the use of various other theoretical criteria in addition to further tests (e.g., cointegration test, feedback from debt to deficit, etc.).

\section{Supplementary information}

Supplementary information accompanies this paper at https://doi.org/10.1186/s40008-019-0161-3.

Additional file 1. WinRATS code to estimate nonlinear unit root tests.

Additional file 2. GUAUSS code to estimate unit root tests with structural break.

\section{Abbreviations}

ADF: Augmented Dickey-Fuller unit-root test; DGP: data-generating process; ESTAR: exponential smooth transition autoregressive; FRR: Fonds de Régulation des Recettes; IFS: the International Financial Statistic database; KPSS: Kwiatkowski-Phillips-Schmidt-Shin unit-root test; KSS: Kapetanios, Shin, and Snell STAR unit-root test; LM: Lagrange multiplier; LSTR: LOGISTIC smooth transition autoregressive; NLADF: nonlinear Augmented Dickey-Fuller unit-root test; NLS: nonlinear least squares; NPG: No-Ponzi-Game; OLS: Ordinary least squares; PIH: permanent income hypothesis; PP: Philips-Perron unit-root test; PVBC: present value budget constraint; QAR: quantiles autoregressive; SETAR: self-exciting threshold autoregressive model; STAR: smooth transition autoregressive; TAR: threshold autoregressive; VAT: value-added tax; WDI: World Development Indicators database.

\section{Acknowledgments}

We owe a huge debt of gratitude to Timo Teräsvirta, Franses and van Dijk, Junsoo Lee, and Aycan Hepsag, for providing JMuITi, GAUSS, and WinRATS codes employed in this research paper. We are grateful for the helpful comments from the editor, and two anonymous referees. Also we thank Sahnoune Nisrine for language editing.

\section{Authors' contributions}

All the authors have equally contributed for scheming the research, studying concepts or design, processing data collection, and calculation so as to write the manuscript. All authors read and approved the final manuscript.

\section{Authors' information}

Both authors are serving as the associate professors at the Faculty of Economics, University Center of Maghnia and Tlemcen University in Algeria. They are also research members of the "Money and financial institutions in the Arab Maghreb Laboratory" (MIFMA) in the Faculty of Economics, Tlemcen University, Algeria.

\section{Funding}

Not available.

Availability of data and materials

The data are compiled from the National Office of Statistics, Ministry of Finance, WDI and IFS.

Ethics approval and consent to participate

Not applicable.

Consent for publication

Not applicable.

Competing interests

The authors declare that they have no competing interests.

\section{Author details}

${ }^{1}$ Faculty of Economics and Management, University Centre of Maghnia, Maghnia, Algeria. ${ }^{2}$ Faculty of Economics and Management, Tlemcen University, Tlemcen, Algeria. 
Received: 13 March 2019 Accepted: 12 August 2019

Published online: 26 August 2019

\section{References}

Afonso A, Rault C (2010) What do we really know about fiscal sustainability in the EU? A panel data diagnostic. Rev World Econ 145(4):731-755

Ahmed S, Rogers JH (1995) Government budget deficits and trade deficits are present value constraints satisfied in longterm data? J Monetary Econ 36(2):351-374

Aldama P (2014) Public debt sustainability under a regime-switching fiscal policy rule. Universite Paris, Paris, p 1

Alesina A, Drazen A (1991) Why are stabilizations delayed? Am Econ Rev 81 (5):1170-1188

Andersen TM, Pedersen LH (2006) Assessing fiscal sustainability and the consequences of reforms. Eur Comm, Bryssels, pp 4-47

Arghyrou MG, Luintel KB (2007) Government solvency: revisiting some EMU countries. J Macroecon 29(2):387-410

Artis M, Marcellino M (2000) The solvency of government finances in Europe, in: fiscal sustainability. In: Presented at the fiscal sustainability, Banca d'Italia, Perugia, Italy, pp. 209-242

Auerbach AJ, Gokhale J, Kotlikoff L (1991) Generational accounts: a meaningful alternative to deficit accounting. Tax Policy Econ 5:55-110

Baharumshah AZ, Lau E (2010) Mean reversion of the fiscal conduct in 24 developing countries. Manchester School 78(4):302-325

Balassone F, Monacelli D (2000) EMU fiscal rules: is there a Gap?. Banca d'Italia, Rome

Barnhill MTM, Kopits MG (2003) Assessing fiscal sustainability under uncertainity (No. 3-79). International Monetary Fund, Washington

Bertola G, Drazen A (1993) Trigger points and budget cuts: explaining the effects of fiscal austerity. Am Econ Rev 83(1):11-26

Bi H (2012) Sovereign default risk premia, fiscal limits, and fiscal policy. Am Econ Rev 56(3):389-410

Blanchard OJ (1990) Can severe fiscal contractions be expansionary? tales of two small european countries: comment. NBER Macroecon Ann 5:111-116

Bohn H (1998) The behavior of US public debt and deficits. Quart J Econ 113(3):949-963

Bravo ABS, Silvestre AL (2002) Intertemporal sustainability of fiscal policies: some tests for European countries. Eur J Polit Econ 18(3):517-528

Breuer JB, McNown R, Wallace MS (2001) Misleading inferences from panel unit root tests with an illustration from purchasing power parity. Rev Int Econ 9(3):482-493

Buiter WH (1985) A guide to public sector debt and deficits. Econ Policy 1(1):13-61

Cassou SP, Shadmani H, Vázquez J (2017) Fiscal policy asymmetries and the sustainability of US government debt revisited. Empir Econ 53(3):1193-1215

Chibi, Benbouziane and Chekouri (2014) The impact of fiscal policy on economic activity over the business cycle: an empirical investigation in the case of Algeria. In: ERF Working Paper 845

Chortareas G, Kapetanios G, Uctum M (2008) Nonlinear alternatives to unit root tests and public finances sustainability: some evidence from Latin American and Caribbean countries. Oxford Bull Econ Stat 70(5):645-663

Cochrane JH (2011) Understanding policy in the great recession: some unpleasant fiscal arithmetic. Am Econ Rev 55(1):2-30

Davig T (2005) Periodically expanding discounted debt: a threat to fiscal policy sustainability? J Appl Econ 20(7):829-840

Eklund B (2003) A nonlinear alternative to the unit root hypothesis (No. 547). In: SSE/EFI working paper series in economics and finance

Fernandez-Huertas Moraga J, Vidal JP (2004) Fiscal sustainability and public debt in an endogenous growth model (No. 395). ECB Working Paper

Feve P, Henin P-Y (2000) Assessing effective sustainability of fiscal policy within the G-7. Oxford Bul Econ Stat 62(2):175-195

Fincke B, Greiner A (2011) Debt sustainability in selected euro area countries: Empirical evidence estimating time-varying parameters. Stud Nonlinear Dyn Econ 15:3

Franses PH, van Dijk D (2003) Nonlinear time series models in empirical finance. Cambridge University Press, New York

Gabriel VJ, Sangduan P (2011) Assessing fiscal sustainability subject to policy changes: a Markov switching cointegration approach. Empir Econ 41(2):371-385

Ghosh AR, Kim JI, Mendoza EG, Ostry JD, Qureshi MS (2013) Fiscal fatigue, fiscal space and debt sustainability in advanced economies. Econ J 123(566):F4-F30

Giammarioli N, Nickel C, Rother P, Vidal J-P (2007) Assessing fiscal soundness—-theory and practice (Occasional Paper Series No. 56). European Central Bank

Gokhale J (2008) Generational accounting. In: Durlauf SN, Blume L (eds) The new Palgrave dictionary of economics (Vol. 6, pp. 631-634). Palgrave Macmillan, Basingstoke, pp 630-633

Hakkio CS, Rush M (1991) Is the budget deficit"too large?". Econ Inq 29(3):429-445

Hamilton JD, Flavin M (1986) On the limitations of government borrowing: a framework for empirical testing. Am Econ Rev 76(4):808-819

Haug AA (1991) Cointegration and government borrowing constraints: evidence for the United States. J Bus Econ Stat 9(1):97-101

Hepsag A (2019) A unit root test based on smooth transitions and nonlinear adjustment. Commun Stat Simul Comput. https://doi.org/10.1080/03610918.2018.1563154

Huang CJ (2006) Public debt sustainability: nonlinear evidence from Taiwan. Feng Chia University, Taiwan. https://www. researchgate.net/publication/254757950_Public_Debt_Sustainability_Nonlinear_Evidence_from_Taiwan

Huang CJ (2014) The sustainability of public debt in Taiwan. Int J Soc Manag Econ Bus Eng 8(7):2180-2183

International Monetary Fund (2002) Assessing sustainability. IMF, Washington, DC 
International Monetary Fund (2011) Modernizing the framework for fiscal policy and public debt sustainability analysis. IMF, Washington, DC

International Monetary Fund (2012) Macroeconomic policy frameworks for resource-rich developing countries. IMF Policy Paper

International Monetary Fund (2013) Staff guidance note for public debt sustainability analysis in market-access countries. IMF, Washington, D.C.

International Monetary Fund (2014) Algeria Selected Issues. IMF Country Report No. 14/34

International Monetary Fund (2018) Algeria selected issues. IMF Country Report No. 168

International Monetary Fund (2019) (Middle East and Central Asia Department): Regional Economic Outlook

Irungu WN, Chevallier J, Ndiritu SW (2019) Regime changes and fiscal sustainability in Kenya. Econ Model. https://doi. org/10.1016/j.econmod.2019.01.009

Jawadi F, Sousa RM (2013) Structural breaks and nonlinearity in US and UK public debts. Appl Econ Lett 20(7):653-657

Kapetanios G, Shin Y, Snell A (2003) Testing for a unit root in the nonlinear STAR framework. J Econometr 112(2):359-379

Krejdl A (2006) Fiscal sustainability: definition, indicators and assessment of czech public finance sustainability. Czech National Bank, Economic Research Department, Na Př́kopě

Kremers JJ (1988) Long-run limits on the US federal debt. Econ Lett 28(3):259-262

Kruse R (2011) A new unit root test against ESTAR based on a class of modified statistics. Stat Pap 52(1):71-85

Lee J, Strazicich MC (2003a) Minimum LM unit root test with one structural break. In: Working paper, Department of Economics, Appalachain State University

Lee J, Strazicich MC (2003b) Minimum Lagrange multiplier unit root test with two structural breaks. Rev Econ Stat 85(4):1082-1089

Leeper EM, Walker TB (2011) Fiscal limits in advanced economies. Econ Papers 30(1):33-47

Legrenzi G, Milas C (2012) Long-Run debt sustainability and threshold adjustments: non-linear empirical evidence from the GIIPS. Economics Bulletin 32(3):2586-2593

Lima LR, Gaglianone WP, Sampaio RM (2008) Debt ceiling and fiscal sustainability in Brazil: a quantile autoregression approach. J Dev Econ 86(2):313-335

Lumsdaine RL, Papell DH (1997) Multiple trend breaks and the unit-root hypothesis. Rev Econ Stat 79(2):212-218

Luukkonen R, Saikkonen P, Teräsvirta T (1988) Testing linearity against smooth transition autoregressive models. Biometrika 75(3):491-499

Mackiewicz-Łyziak J, Łyziak T (2019) A new test for fiscal sustainability with endogenous sovereign bond yields: evidence for EU economies. Econ Model. https://doi.org/10.1016/j.econmod.2019.01.001

Martin GM (2000) US deficit sustainability: a new approach based on multiple endogenous breaks. J Appl Econometr 15(1):83-105

Ng S, Perron P (2001) LAG length selection and the construction of unit root tests with good size and power. Econometrica 69(6):1519-1554

Ostry JD, Ghosh AR, Kim JI, Qureshi MS (2010) Fiscal space. International Monetary Fund, Research Department, Washington

Perron P (1989) The great crash, the oil price shock, and the unit root hypothesis. Econometrica 57(6):1361-1401

Piergallini A, Postigliola M (2013) Non-linear budgetary policies: evidence from 150 years of Italian public finance. Econ Lett 121(3):495-498

Quintos CE (1995) Sustainability of the deficit process with structural shifts. J Bus Econ Stat 13(4):409-417

Saikkonen P, Lütkepohl H (2002) Testing for a unit root in a time series with a level shift at unknown time. Econometr Theory 18(2):313-348

Sarvi T (2011) Some approaches for assessing the sustainability of public finances. Master's thesis. Aalto University School of Economics

Shiamptanis C (2015) Risk assessment under a nonlinear fiscal policy rule. Econ Inq 53(3):1539-1555

Smith GW, Zin SE (1991) Persistent deficits and the market value of government debt. J Appl Econ 6(1):31-44

Sollis R (2009) A simple unit root test against asymmetric STAR nonlinearity with an application to real exchange rates in Nordic countries. Econ Model 26(1):118-125

Teräsvirta T (1994) Specification, estimation, and evaluation of smooth transition autoregressive models. J Am Stat Assoc 89(425):208-218

Trehan B, Walsh CE (1988) Common trends, the government's budget constraint, and revenue smoothing. J Econ Dyn Control 12(2-3):425-444

Uctum M, Wickens M (2000) Debt and deficit ceilings, and sustainability of fiscal policies: an intertemporal analysis. Oxford Bull Econ Stat 62(2):197-222

Uctum M, Thurston T, Uctum R (2006) Public debt, the unit root hypothesis and structural breaks: a multi-country analysis. Economica 73(289):129-156

Van Ewijk C, Draper N, ter Rele H, Westerhout EWMT (2006) Ageing and the sustainability of Dutch public finances. CPB Netherlands Bureau for Economic Policy Analysis, The Hague

Wickens MR, Uctum M (1993) The sustainability of current account deficits: a test of the US intertemporal budget constraint. J Econ Dyn Control 17(3):423-441

Wilcox DW (1989) The sustainability of government deficits: implications of the present-value borrowing constraint. J Money Credit Banking 21(3):291-306

Zivot E, Andrews D (1992) Further evidence of the great crash, the oil-price shock and the unit-root hypothesis'. J Bus Econ Stat 10:251-270

\section{Publisher's Note}

Springer Nature remains neutral with regard to jurisdictional claims in published maps and institutional affiliations. 